\title{
MARKOVKETENS EN HUN TOEPASSINGEN
}

\author{
door G. R. Mustert
}

$\mathrm{Bij}$ een groot aantal bedrijfseconomische keuzeproblemen kan het te bestuderen object (een voorraad, een machine, de schuld van een debiteur, een loket, een telefooncentrale e.d.) zich in een aantal te onderscheiden toestanden bevinden. Als de toestand van het object van tijd tot tijd verandert en die veranderingen plaatsvinden op een wijze die aan bepaalde voorwaarden voldoet, kan men het gedrag van het te bestuderen object beschrijven met behulp van de theorie van de Markovketens. Een dergelijke beschrijving kan goede diensten bewijzen bij de bepaling van de beste keuze uit de mogelijke beslissingsalternatieven. In dit artikel worden de grondbegrippen van de theorie van de Markovketens behandeld en toegelicht aan de hand van enige eenvoudige voorbeelden.

\section{Inleiding}

Het te bestuderen object geven wij aan met het abstracte begrip systeem. Een systeem kan in verschillende toestanden verkeren. Wij beschouwen slechts systemen waarvan de toestanden beschreven kunnen worden met behulp van één of meer kwantitatieve grootheden. De keuze van de toestandsgrootheden is afhankelijk van het keuzeprobleem dat tot de bestudering van het systeem aanleiding heeft gegeven. Zo beschouwt men bij een voorraad als toestandsgrootheid doorgaans het aantal eenheden in voorraad en bij een telefooncentrale het aantal bezette lijnen.

Als het systeem achtereenvolgens verschillende toestanden aanneemt zeggen wij dat een proces plaatsvindt. Vaak wordt de wijze waarop de toestandsveranderingen plaatsvinden mede bepaald door een kansmechanisme. Het staat dan tevoren niet met zekerheid vast wat het resultaat van de toestandsverandering zal zijn. Als bij een telefooncentrale die over drie lijnen beschikt op een bepaald moment één lijn bezet is, gaat het systeem bij de volgende overgang over in één van de toestanden 0 en 2 : in toestand 0 als het gevoerde gesprek eerder wordt beëindigd dan een nieuw gesprek wordt begonnen, in toestand 2 als eerder een nieuw gesprek wordt begonnen dan het gevoerde gesprek wordt beëindigd. Welk van beide gebeurtenissen zich realiseert is niet met zekerheid voorspelbaar. Men kan slechts de kansen op elk van beide mogelijke gebeurtenissen aangeven.

Indien het systeem slechts op duidelijk te onderscheiden tijdstippen in een andere toestand overgaat, kunnen wij het proces beschrijven door de rij van ach tereenvolgende toestanden van het systeem. Een dergelijke rij noemen wij een keten. In het vervolg beschouwen wij slechts processen die door een keten kunnen worden beschreven en voorlopig nemen wij aan dat het aantal mogelijke toestanden eindig is en gelijk aan $n(n>1)$.

De kans dat een systeem dat zich in toestand $i(i=1,2, \ldots, n)$ bevindt bij de volgende overgang overgaat naar toestand $j(j=1,2, \ldots, n)$ noemen wij 
de overgangswh $\left.{ }^{1}\right) \mathrm{p}_{\mathrm{ij}}$. Voor elke $\mathrm{i}$ en elke $\mathrm{j}$ moet gelden dat $0 \leqq \mathrm{p}_{\mathrm{ij}} \leqq 1$ en voor elke i moet gelden dat $p_{i 1}+p_{i 2}+\ldots+p_{i n}=1$. Voor elke i zijn er dus $\mathrm{n}$ overgangswhn. Er zijn n mogelijke toestanden i. Er zijn dus nxn overgangswhn. Gewoonlijk worden de overgangswhn samengenomen in een matrix van overgangswhn:

$\mathrm{j}=$
$\mathrm{i}=1$
2
$\cdot$
$\cdot$
$\cdot$
$\mathrm{n}$$\left[\begin{array}{cccc}\mathrm{p}_{11} & \mathrm{p}_{12} & \ldots & \mathrm{p}_{1 \mathrm{n}} \\ \mathrm{p}_{21} & \mathrm{p}_{22} & \ldots & \mathrm{p}_{2 \mathrm{n}} \\ \cdot & \cdot & & \cdot \\ \cdot & \cdot & & \cdot \\ \cdot & \cdot & & \cdot \\ \mathrm{p}_{\mathrm{n} 1} & \mathrm{p}_{\mathrm{n} 2} & \ldots & \mathrm{p}_{\mathrm{nn}}\end{array}\right]$

De overgangswhn zijn voorwaardelijke kansen: $p_{i j}$ is de kans op een overgang naar toestand $j$ onder de voorwaarde dat de overgang plaatsvindt vanuit toestand $i$. Als de kans op een overgang naar toestand $j$ afhankelijk is van de toestanden waarin het systeem geweest is voordat toestand $\mathrm{j}$ werd bereikt, wordt de keten een Markovketen genoemd naar de Russische wiskundige A. A. MARKOV (1856-1922) die de grondslagen van de theorie van de naar hem genoemde ketens heeft geformuleerd. Als de kans op een overgang naar toestand $\mathrm{j}$ slechts afhankelijk is van de toestand $\mathrm{i}$ vanwaaruit de overgang naar $\mathrm{j}$ plaatsvindt maar niet van de toestanden waarin het systeem geweest is voordat toestand i werd bereikt, heet de Markovketen enkelvoudig. Wij beschouwen in het vervolg slechts enkelvoudige Markovketens en zullen daarbij aannemen dat de overgangswhn bij elke overgang dezelfde zijn. Wij zeggen dan dat de overgangswhn stationair zijn.

Wij lichten het voorgaande toe aan de hand van een tweetal voorbeelden.

\section{Voorbeeld 1}

Wij beschikken over een groot aantal rode en zwarte ballen. In een vaas bevinden zich één rode en drie zwarte ballen. Wij trekken aselect een bal uit de vaas en leggen er een bal van de andere (niet getrokken) kleur voor in de plaats. Deze handeling wordt vijfmaal uitgevoerd. Wat is de kans dat bij de vijfde trekking een rode bal wordt getrokken?

De vaas met ballen is het systeem. De kans bij de vijfde trekking een rode bal te trekken wordt bepaald door het aantal rode ballen in de vaas na vier trekkingen. Wij beschouwen daarom het aantal rode ballen in de vaas als toestandsgrootheid. De mogelijke toestanden zijn dan 0, 1, 2, 3 en 4. Bij elke

\footnotetext{
1) $w h=$ waarschijnlijkheid, whn $=$ waarschijnlijkheden.
} 
trekking verandert de toestand van het systeem. Als er 0 rode ballen in de vaas zijn, wordt met kans 1 een zwarte bal getrokken en vervangen door een rode. Vanuit toestand 0 gaat het systeem met kans 1 over in toestand 1 . Als er 1 rode bal in de vaas is, wordt die rode bal met kans $\frac{1}{4}$ getrokken en vervangen door een zwarte. Met kans $\frac{3}{4}$ wordt dan een zwarte bal getrokken en vervangen door een rode. Vanuit toestand 1 gaat het systeem dus met kans $\frac{1}{4}$ over in toestand 0 en met kans $\frac{3}{4}$ in toestand 2 . Op dezelfde wijze kunnen de andere overgangswhn worden bepaald. De matrix van overgangswhn wordt gegeven door:

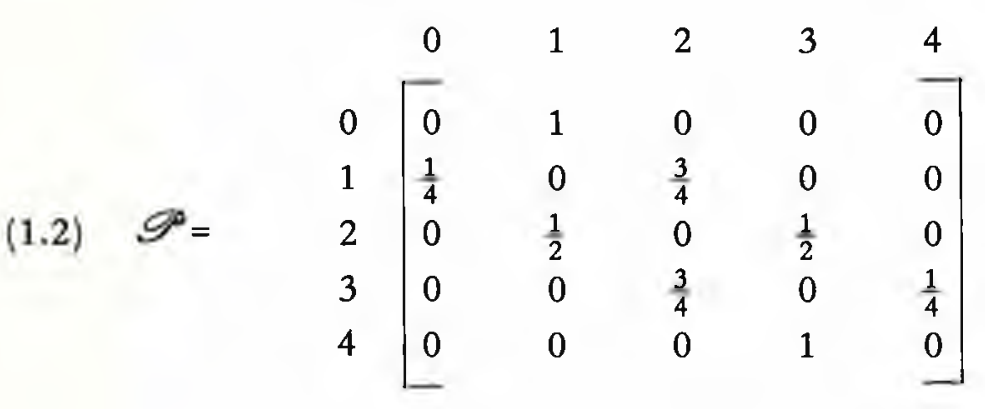

Het proces kan dus worden beschreven door een enkelvoudige Markovketen, omdat de overgangswhn afhankelijk zijn van de uitgangstoestand maar niet van daaraan voorafgaande toestanden.

In paragraaf 2 zal worden behandeld op welke wijze het mogelijk is met behulp van de matrix van overgangswhn de gevraagde kans te bepalen.

\section{Voorbeeld 2}

Wij beschouwen een situatie waarin van een artikel een aantal exemplaren in voorraad wordt gehouden om aan een onregelmatige vraag te kunnen voldoen. Wij nemen aan dat een eventuele aanvulling van de voorraad plaatsvindt aan het begin van een week en dat de vraag naar exemplaren van het artikel in de loop van een week een toevalsvariabele $\underline{d}^{2}$ ) is waarvan de kansverdeling dezelfde is voor elke week en gegeven wordt door:

$$
P[\underline{d}=0]=P[\underline{d}=1]=P[\underline{d}=2]=P[d=3]=\frac{1}{4} \text {. }
$$

Het voorraadniveau wordt aan het begin van elke week onderzocht. Als de beschikbare voorraad dan gelijk is aan nul exemplaren, wordt de voorraad onmiddellijk aangevuld tot drie exemplaren. Als de beschikbare voorraad positief is vindt geen aanvulling plaats.

De voorraad is het systeem waarvan de toestand wordt gegeven door de beschikbare voorraad aan het begin van een week. Wij definiëren als mogelijke toestanden $3,2,1,0,-1$ en -2 , waarbij een negatieve waarde een

2) Toevalsvariabelen worden onderstreept.

$\begin{array}{lll}m a b & b l z . & 214\end{array}$ 
tekort in de voorgaande week betekent waarin moet worden voorzien door het verrichten van noodinkopen. Volgens de regels van het voorraadbeheer worden de voorraadniveau's van twee opeenvolgende weken met elkaar verbonden door de relatie:

$$
\begin{gathered}
\mathrm{j}=\mathrm{i}-\mathrm{d} \text { als } 0<\mathrm{i} \leqq 3, \\
3-\mathrm{d} \text { als } \mathrm{i} \leq 0 .
\end{gathered}
$$

De voorraadniveau's van de opeenvolgende weken vormen dus een enkelvoudige Markovketen. Met behulp van de kansverdeling van de vraag per week en relatie (1.3) kan de matrix van overgangswhn worden opgesteld die gegeven wordt door:

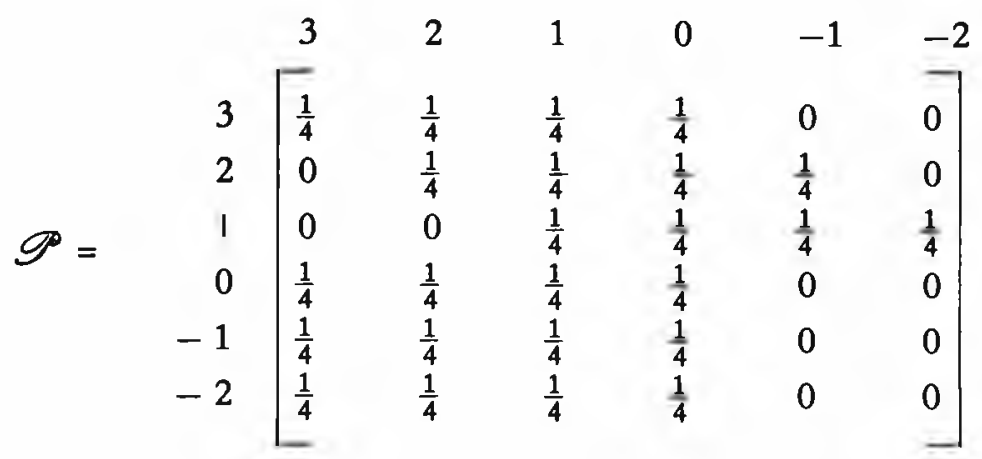

In het navolgende zal worden uitgelegd hoe het met behulp van deze beschrijving van het proces mogelijk is het voorraadbeheer te evalueren en te verbeteren.

\section{Kansverdelingen in enkelvoudige Markovketens}

In paragraaf 1 gingen wij uit van één bepaalde begintoestand $i$. Het is echter ook mogelijk dat er niet één bepaalde uitgangstoestand is, maar dat de uitgangstoestand een kansverdeling heeft bepaald door de aanvangswhn:

$$
\left(\mathrm{p}_{1}^{(0)}, \mathrm{p}_{2}^{(0)}, \ldots, \mathrm{p}_{\mathrm{n}}^{(0)}\right) \text {. }
$$

Deze vector ${ }^{3}$ ) die wij aangeven met $\left(\mathrm{P}^{(0)}\right)^{\prime}$ beschrijft de aanvangsverdeling. De kans dat een systeem na één overgang in toestand $\mathrm{j}$ is en voor die overgang in toestand $i$ is gelijk aan $\mathrm{p}_{\mathrm{i}}^{(0)} \mathrm{p}_{\mathrm{ij}}$. De onvoorwaardelijke of absolute kans dat het systeem na één overgang in toestand $\mathrm{j}$ is wordt gegeven door de som van $\mathrm{p}_{\mathrm{i}}^{(0)} \mathrm{p}_{\mathrm{ij}}$ over alle mogelijke begintoestanden, zodat:

$$
\mathrm{p}_{\mathrm{j}}^{(1)}=\sum_{\mathrm{i}=1}^{\mathrm{n}} \mathrm{p}_{\mathrm{i}}^{(0)} \mathrm{p}_{\mathrm{ij}}, \quad \mathrm{j}=1,2, \ldots, \mathrm{n} \text {. }
$$

3) Een vector $X$ wordt gedefinieerd als kolovector. De getransponeerde $X^{1}$ is een rijvector. 
Uitgaande van de absolute whn na één overgang en de overgangswhn kunnen op dezelfde wijze de absolute whn na twee overgangen worden bepaald, enz., zodat algemeen geldt dat:

$$
\left(\mathrm{P}^{(\mathrm{m})}\right)^{\prime}=\left(\mathrm{P}^{(\mathrm{m}-1)}\right)^{\prime}, \mathscr{P} \quad \mathrm{m}=1,2, \ldots
$$

Wij lichten dit toe aan de hand van Voorbeeld 1.

Voorbeeld 1 (vervolg)

Omdat het systeem aanvangt vanuit toestand 1 wordt de aanvangsverdeling gegeven door:

$$
\left(\mathrm{P}^{(0)}\right)^{\prime}=\left(\begin{array}{lllll}
0 & 1 & 0 & 0 & 0
\end{array}\right) .
$$

De absolute whn na één overgang worden dus gegeven door:

$$
\mathrm{P}_{\mathrm{j}}^{(1)}=\sum_{\mathrm{i}=0}^{4} \mathrm{p}_{\mathrm{i}}^{(0)} \mathrm{p}_{\mathrm{ij}}=\mathrm{p}_{1}^{(0)} \mathrm{p}_{1 \mathrm{j}}=\mathrm{p}_{1 \mathrm{j}}, \quad \mathrm{j}=0,1, \ldots, 4,
$$

zodat:

$$
\left(\mathrm{P}^{(1)}\right)^{\prime}=\left(\begin{array}{lllll}
\frac{1}{4} & 0 & \frac{3}{4} & 0 & 0
\end{array}\right) .
$$

De absolute whn na twee overgangen worden dus gegeven door:

$$
\mathrm{p}_{\mathrm{j}}^{(2)}=\sum_{\mathrm{i}=0}^{4} \mathrm{p}_{\mathrm{i}}^{(1)} \mathrm{p}_{\mathrm{ij}}=\mathrm{p}_{0}^{(1)} \mathrm{p}_{0 \mathrm{j}}+\mathrm{p}_{2}^{(1)} \mathrm{p}_{2 \mathrm{j}}=\frac{1}{4} \mathrm{p}_{0 \mathrm{j}}+\frac{3}{4} \mathrm{p}_{2 \mathrm{j}}, \mathrm{j}=0,1, \ldots, 4,
$$

zodat:

$$
\left(\mathrm{P}^{(2)}\right)^{\prime}=\left(\begin{array}{lllll}
0 & \frac{5}{8} & 0 & \frac{3}{8} & 0
\end{array}\right) .
$$

De absolute whn na drie overgangen worden dus gegeven door:

$$
p_{j}^{(3)}=\sum_{i=0}^{4} p_{i}^{(2)} p_{i j}=p_{1}^{(2)} p_{i j}+p_{3}^{(2)} p_{3 j}=\frac{5}{8} p_{1 j}+\frac{3}{8} p_{3 j}, j=0,1, \ldots, 4,
$$

zodat:

$$
\left(\mathrm{P}^{(3)}\right)^{\prime}=\left(\begin{array}{lllll}
\frac{5}{32} & 0 & \frac{3}{4} & 0 & \frac{3}{32}
\end{array}\right) .
$$

De absolute whn na vier overgangen worden dus gegeven door:

$$
\begin{aligned}
& \mathrm{p}_{\mathrm{j}}^{(4)}=\sum_{\mathrm{i}=0}^{4} \mathrm{p}_{\mathrm{i}}^{(3)} \mathrm{p}_{\mathrm{ij}}=\mathrm{p}_{0}^{(3)} \mathrm{p}_{0 \mathrm{j}}+\mathrm{p}_{2}^{(3)} \mathrm{p}_{2 \mathrm{j}}+\mathrm{p}_{4}^{(3)} \mathrm{p}_{4 \mathrm{j}}= \\
& =\frac{5}{32} \mathrm{p}_{0 \mathrm{j}}+\frac{3}{4} \mathrm{p}_{2 \mathrm{j}}+\frac{3}{32} \mathrm{p}_{4 \mathrm{j}}, \quad \mathrm{j}=0,1, \ldots, 4,
\end{aligned}
$$

zodat:

$$
\left(\mathrm{P}^{(4)}\right)^{\prime}=\left(\begin{array}{lllll}
0 & \frac{1}{3} \frac{7}{2} & 0 & \frac{15}{32} & 0
\end{array}\right) .
$$

mab blz. 216 
Gevraagd werd de kans dat bij de vijfde trekking een rode bal wordt getrokken. Na vier trekkingen is met kans $\frac{17}{32}$ één rode bal in de vaas en zijn met kans $\frac{15}{32}$ drie rode ballen in de vaas. Als er één rode bal is wordt die met kans $\frac{1}{4}$ getrokken, als er drie rode ballen zijn wordt één van hen met kans $\frac{3}{4}$ getrokken. De kans op een rode bal bij de vijfde trekking is dus gelijk aan:

$$
\frac{1}{4} \cdot \frac{17}{32}+\frac{3}{4} \cdot \frac{15}{32}=\frac{31}{6} \frac{1}{4} \text {. }
$$

In plaats van de absolute whn na elke overgang te beschouwen is het ook mogelijk uitgaande van de aanvangsverdeling en de matrix van overgangswhn de absolute whn na $m$ overgangen rechtstreeks te bepalen. Wij beschouwen daartoe $p_{i j}^{(m)}$, de kans vanuit toestand $i$ in precies $m$ overgangen in toestand $j$ te $z i j n$. $Z_{O}$ is $P_{i j}^{(2)}$ de kans in twee overgangen van toestand $i$ in toestand $j$ te komen. Deze toestandsverandering vindt plaats via een toestand $k$ na de eerste overgang $(k=1,2, \ldots, n)$. De kans van i naar $k$ te gaan is $p_{1 k}$. De kans van $k$ naar $j$ te gaan is $p_{k}$. De kans van $i$ via $k$ naar $j$ te gaan is dus gelijk aan $\mathrm{p}_{\mathrm{ik}} \mathrm{p}_{\mathrm{kj}}$. De onvoorwaardelijke kans van $\mathrm{i}$ naar $\mathrm{j}$ te gaan in twee overgangen wordt gegeven door de som van $\mathrm{p}_{\mathrm{ik}} \mathrm{p}_{\mathrm{kj}}$ over alle mogelijke tussentoestanden $k$, zodat:

$$
\mathrm{p}_{\mathrm{ij}}^{(2)}=\sum_{\mathrm{k}=1}^{\mathrm{n}} \mathrm{p}_{\mathrm{ik}} \mathrm{p}_{\mathrm{kj}}, \quad \mathrm{i}, \mathrm{j}=1,2, \ldots, \mathrm{n} .
$$

Algemeen geldt dat:

$$
\mathrm{p}_{\mathrm{ij}}^{(\mathrm{m})}=\sum_{\mathrm{k}=1}^{\mathrm{n}} \mathrm{p}_{\mathrm{ik}}^{(\mathrm{m}-1)} \mathrm{p}_{\mathrm{kj}}, \quad \mathrm{i}, \mathrm{j}=1,2, \ldots, \mathrm{n} .
$$

De vorm van vergelijking (2.5) vertoont grote overeenkomst met de vorm van een matrixprodukt. Het ligt daarom voor de hand om de volgende matrix in te voeren:

$$
\mathscr{P}(m)=\left[\begin{array}{cccc}
p_{11}^{(m)} & p_{12}^{(m)} & \ldots & p_{1 n}^{(m)} \\
p_{21}^{(m)} & p_{22}^{(m)} & \cdots & p_{2 n}^{(m)} \\
\cdot & \cdot & & \cdot \\
\cdot & \cdot & & \cdot \\
p_{n 1}^{(m)} & p_{n 2}^{(m)} & \cdots & p_{n n}^{(m)}
\end{array}\right]
$$

$$
\mathrm{m}=1,2, \ldots
$$

Voor $\mathrm{m}=1$ zijn de matrixelementen de overgangswhn $\mathrm{p}_{\mathrm{ij}}$. Met behulp van (2.6) kunnen wij (2.5) schrijven als:

$$
\mathscr{P}(m)=\mathscr{P}(m-1) \cdot \mathscr{P} .
$$


Substitueren wij hierin achtereenvolgens $m=2,3, \ldots$ dan vinden wij dat de matrix $\mathscr{P}^{(\mathrm{m})}$ het matrixprodukt is van $\mathrm{m}$ factoren $\mathscr{P}^{\text {, zodat: }}$

$$
\mathscr{P}^{(\mathrm{m})}=\mathscr{P}^{\mathrm{m}} .
$$

Wij lichten dit toe aan de hand van Voorbeeld 1.

Voorbeeld 1 (vervolg)

Wij zijn geïnteresseerd in het aantal rode ballen in de vaas na vier trekkingen. De vierde macht van de matrix van overgangswhn wordt gegeven door:

\begin{tabular}{|c|c|c|c|c|c|c|}
\hline & & 0 & 1 & 2 & 3 & 4 \\
\hline & 0 & $\frac{5}{32}$ & 0 & $\frac{3}{4}$ & 0 & $\frac{3}{32}$ \\
\hline & 1 & 0 & $\frac{17}{32}$ & 0 & $\frac{15}{32}$ & 0 \\
\hline $\mathscr{P}^{4}=$ & 2 & $\frac{1}{8}$ & 0 & $\frac{3}{4}$ & 0 & $\frac{1}{8}$ \\
\hline & 3 & 0 & $\frac{15}{32}$. & 0 & $\frac{17}{32}$ & 0 \\
\hline & 4 & $\frac{3}{32}$ & 0 & $\frac{3}{4}$ & 0 & $\frac{5}{32}$ \\
\hline
\end{tabular}

De aanvangsverdeling wordt gegeven door:

$$
\left(P^{(0)}\right)^{\prime}=\left(\begin{array}{lllll}
0 & 1 & 0 & 0 & 0
\end{array}\right) .
$$

De absolute whn na vier overgangen worden dus gegeven door:

$$
\mathrm{p}_{\mathrm{j}}^{(4)}=\sum_{\mathrm{i}=0}^{4} \mathrm{p}_{\mathrm{i}}^{(0)} \mathrm{p}_{\mathrm{ij}}^{(4)}=\mathrm{p}_{1}^{(0)} \mathrm{p}_{1 \mathrm{j}}^{(4)}=\mathrm{p}_{1 \mathrm{j}}^{(4)}, \quad \mathrm{j}=0,1, \ldots, 4,
$$

zodat:

$$
\left(P^{(4)}\right)^{\prime}=\left(\begin{array}{lllll}
0 & \frac{17}{32} & 0 & \frac{15}{32} & 0
\end{array}\right),
$$

waarna de redenering op dezelfde wijze verloopt als bij de eerdere uitwerking.

Wij gaan nu de matrix $\mathscr{P}^{(\mathrm{m})}$ beschouwen voor $\mathrm{m} \rightarrow \infty$. Voordat wij daartoe overgaan moeten wij nog het begrip periodiciteit introduceren. Wij doen dat aan de hand van de matrix van overgangswhn van Voorbeeld 1 met een verandering in de volgorde van de toestanden: 


\begin{tabular}{|c|c|c|c|c|c|c|}
\hline & & 0 & 2 & 4 & 1 & 3 \\
\hline & 0 & 0 & 0 & 0 & 1 & 0 \\
\hline & 2 & 0 & 0 & 0 & $\frac{1}{2}$ & $\frac{1}{2}$ \\
\hline $\mathscr{P}=$ & 4 & 0 & 0 & 0 & 0 & 1 \\
\hline & 1 & $\frac{1}{4}$ & $\frac{3}{4}$ & 0 & 0 & 0 \\
\hline & 3 & 0 & $\frac{3}{4}$ & $\frac{1}{4}$ & 0 & 0 \\
\hline
\end{tabular}

Voor de eerste trekking is er één rode bal in de vaas. Na de eerste trekking is het systeem dus in toestand 0 of 2 , na de tweede trekking in 1 of 3 , na de derde trekking in 0,2 of 4 , enz. $\mathrm{Na}$ een oneven aantal trekkingen is het systeem in één van de toestanden 0,2 en 4, na een even aantal trekkingen in één van de toestanden 1 en 3 . Als de verzameling van mogelijke toestanden kan worden gesplitst in deelverzamelingen $A_{1}, A_{2}, \ldots, A_{h}$ zodanig dat voor $i$ $=1,2, \ldots, h$ vanuit een toestand die tot $A_{i}$ behoort alleen een overgang mogelijk is naar een toestand die tot $A_{i+1}$ behoort (met $A_{h+1}=A_{1}$ ), dan zeggen wij dat de keten periodiek is met periode $h$. $\mathrm{Zo}$ is de keten van Voorbeeld 1 periodiek met periode 2. Een niet-periodieke keten is dus eigenlijk een keten met periode 1 .

Als een keten niet-periodiek is en elke toestand vanuit elke toestand kan worden bereikt (wat niet noodzakelijk in één overgang hoeft mogelijk te zijn), dan kan men bewijzen dat $\mathscr{P}(\mathrm{m})=\mathscr{P}^{\mathrm{m}}$ voor $\mathrm{m} \rightarrow \infty$ nadert tot een limiet $\mathscr{Q}$, die bestaat uit $\mathrm{n}$ identieke rijen $\mathscr{Q}$, waarin alle elementen positief zijn. Dus geldt dat:

$$
Q=\lim _{m \rightarrow \infty}\left[\begin{array}{cccc}
\mathrm{p}_{11}^{(m)} & \mathrm{p}_{12}^{(m)} & \ldots & \mathrm{p}_{1 n}^{(m)} \\
\mathrm{p}_{21}^{(m)} & \mathrm{p}_{22}^{(m)} & \ldots & \mathrm{p}_{2 n}^{(m)} \\
\cdot & \cdot & & \cdot \\
\cdot & \cdot & & \cdot \\
\mathrm{p}_{n 1}^{(m)} & \mathrm{p}_{n 2}^{(m)} & \ldots & \mathrm{p}_{n n}^{(m)}
\end{array}\right]=\left[\begin{array}{cccc}
\mathrm{q}_{1} & \mathrm{q}_{2} & \ldots & \mathrm{q}_{n} \\
\mathrm{q}_{1} & \mathrm{q}_{2} & \ldots & \mathrm{q}_{n} \\
\cdot & \cdot & & \cdot \\
\cdot & \cdot & & \cdot \\
\cdot & \cdot & & \cdot \\
\mathrm{q}_{1} & \mathrm{q}_{2} & \ldots & \mathrm{q}_{n}
\end{array}\right]
$$

waarin $q_{j}>0(j=1,2, \ldots, n)$.

$\mathrm{Q}$ wordt de invariante kansverdeling van de Markovketen genoemd. De kansen $q_{j}$ kunnen als volgt worden geïnterpreteerd. Stel dat men het systeem gedurende een zeer groot aantal overgangen niet heeft gadegeslagen. De kans dat het systeem zich dan in toestand $\mathrm{j}$ bevindt $\mathrm{zal}$ dan bij benadering gelijk zijn aan $q_{j}$, ongeacht de toestand waarin het systeem zich bevond bij het begin van dat zeer grote aantal overgangen. 
Ook na een zeer groot aantal overgangen blijft de matrix $\mathscr{P}$ van overgangswhn elke overgang beschrijven. Dat wil zeggen dat de kans om bij een ver af gelegen overgang in toestand $j$ te komen gelijk is aan:

$$
\text { (2.10) } \sum_{i=1}^{n} q_{i} p_{i j}, \quad i \neq j \text {. }
$$

De kans om bij een dergelijke overgang toestand $\mathrm{j}$ te verlaten is gelijk aan:

$$
\sum_{k=1}^{n} q_{j} p_{j k}=q_{j k} \sum_{=1}^{n} p_{j k}, \quad k \neq j \text {. }
$$

Wij tellen bij (2.10) en (2.11) $\mathrm{q}_{\mathrm{j}} \mathrm{p}_{\mathrm{jj}}$ op en trekken (2.10) van (2.11) af:

$$
q_{j} \sum_{k}^{n} p_{j k}-\sum_{i=1}^{n} q_{i} p_{i j}=q_{j}-\sum_{i=1}^{n} q_{i} p_{i j} \text {. }
$$

Men kan bewijzen dat dit verschil gelijk is aan nul, zodat geldt dat:

$$
q_{j}=\sum_{i=1}^{n} q_{j} p_{i j}, \quad j=1,2, \ldots, n \text {. }
$$

De invariante verdeling kan dus worden opgevat als een evenwichtsverdeling. De krachten die het systeem vanuit toestand $\mathrm{j}$ willen doen overgaan in een andere toestand worden volledig gecompenseerd door de krachten die het systeem vanuit een willekeurige toestand willen doen overgaan in toestand $\mathrm{j}$. Het stelsel vergelijkingen (2.12), dat als volgt kan worden uitgeschreven:

$$
\begin{aligned}
& q_{1}=p_{11} q_{1}+p_{21} q_{2}+\ldots+p_{n 1} q_{n}, \\
& q_{2}=p_{12} q_{1}+p_{22} q_{2}+\ldots+p_{n 2} q_{n}, \\
& \ldots \ldots \ldots \ldots \ldots \ldots \ldots \ldots \ldots+\ldots \ldots+p_{n n} q_{n},
\end{aligned}
$$

makkt het tesamen met de voorwaarde:

$$
\mathrm{q}_{1}+\mathrm{q}_{2}+\ldots+\mathrm{q}_{\mathrm{n}}=1
$$

mogelijk de invariante kansverdeling te bepalen.

Wij lichten deze werkwijze toe aan de hand van Voorbeeld 2.

Voorbeeld 2 (vervolg)

De keten is niet-periodiek en elke toestand kan vanuit elke toestand worden bereikt. De vergelijkingen (2.12) luiden voor matrix (1.4): 


$$
\begin{aligned}
& q_{3}=\frac{1}{4} q_{3}+\frac{1}{4} q_{0}+\frac{1}{4} q_{-1}+\frac{1}{4} q_{-2}, \\
& q_{2}=\frac{1}{4} q_{3}+\frac{1}{4} q_{2}+\frac{1}{4} q_{0}+\frac{1}{4} q_{-1}+\frac{1}{4} q_{-2}, \\
& q_{1}=\frac{1}{4} q_{3}+\frac{1}{4} q_{2}+\frac{1}{4} q_{1}+\frac{1}{4} q_{0}+\frac{1}{4} q_{-1}+\frac{1}{4} q_{-2}, \\
& q_{0}=\frac{1}{4} q_{3}+\frac{1}{4} q_{2}+\frac{1}{4} q_{1}+\frac{1}{4} q_{0}+\frac{1}{4} q_{-1}+\frac{1}{4} q_{-2}, \\
& q_{-1} \quad+\frac{1}{4} q_{2}+\frac{1}{4} q_{1}, \\
& q_{-2} \quad+\frac{1}{4} q_{1},
\end{aligned}
$$

en:

$$
\mathrm{q}_{3}+\mathrm{q}_{2}+\mathrm{q}_{1}+\mathrm{q}_{0}+\mathrm{q}_{-1}+\mathrm{q}_{-2}=1 \text {. }
$$

De oplossing van dit stelsel luidt:

$$
q_{3}=\frac{9}{64}, q_{2}=\frac{3}{16}, q_{1}=\frac{1}{4}, q_{0}=\frac{1}{4}, q_{-1}=\frac{7}{64}, q_{-2}=\frac{1}{16} \text {. }
$$

$\mathrm{Na}$ een zeer groot aantal weken is de kans dat het systeem wordt aangetroffen in bijv. toestand 3 gelijk aan $\frac{9}{64}$. Wij zullen deze invariante kansen in het vervolg gebruiken bij de evaluatie van het voorraadbeheer.

Vaak kan niet elke toestand vanuit elke toestand worden bereikt. Er kunnen toestanden zijn waarin het systeem niet meer terugkeert wanneer die toestanden eenmaal verlaten zijn. Dergelijke toestanden worden doorgangstoestanden genoemd in tegenstelling tot de terugkeertoestanden waarin het systeem regelmatig terugkeert. Soms is er sprake van toestanden die als ze eenmaal bereikt zijn nooit meer verlaten worden. Dergelijke toestanden worden absorberende toestanden genoemd. Wij lichten deze begrippen toe aan de hand van Voorbeeld 3.

\section{Voorbeeld 3}

Een groothandel schat de maandelijks te treffen voorziening voor dubieuze debiteuren met behulp van een Markovketen. Een detaillist-afnemer is een systeem waarvan de toestand wordt gevormd door de leeftijd van de oudste openstaande schuld van de debiteur. Als een debiteur zijn schuld geheel voldoet, gaat hij naar toestand 0 en verdwijnt uit de debiteurenadministratie. Als de oudste openstaande schuld van een debiteur minder dan 1, 2 resp. 3 maanden oud is, verkeert die debiteur in toestand 1,2 resp. 3 . Als de oudste openstaande schuld van een debiteur meer dan drie maanden oud is, gaat de debiteur naar toestand 4 en verdwijnt uit de debiteurenadministratie. Zijn schuld wordt als oninbaar afgeboekt. (Als een dergelijke debiteur later alsnog zijn schuld geheel of gedeeltelijk voldoet, wordt dat opgevat als een afzonderlijke transactie die buiten de debiteurenadministratie omgaat.) Als een debiteur een deel van zijn schuld voldoet, gaat hij over naar de toestand die correspondeert met de leeftijd van het oudste deel van de resterende schuld.

Als de kredietwaardigheid van een debiteur onafhankelijk is van de grootte van zijn openstaande schtid, van welk deêl valthet debiteurentegoed moet 
dan worden verwacht dat het oninbaar zal blijken, als $50 \%$ van het tegoed in toestand 1 is, $30 \%$ in toestand 2 en $20 \%$ in toestand 3 ?

Stel dat de matrix van overgangswhn gegeven wordt door:

\begin{tabular}{|c|c|c|c|c|c|c|}
\hline & & 0 & 1 & 2 & 3 & 4 \\
\hline & 0 & 1 & 0 & 0 & 0 & 0 \\
\hline & 1 & $\frac{1}{4}$ & $\frac{1}{2}$ & $\frac{1}{4}$ & 0 & 0 \\
\hline $\mathscr{D}=$ & 2 & $\frac{1}{4}$ & $\frac{1}{4}$ & $\frac{1}{4}$ & $\frac{1}{4}$ & 0 \\
\hline & 3 & $\frac{1}{8}$ & $\frac{1}{8}$ & $\frac{1}{4}$ & $\frac{1}{4}$ & $\frac{1}{4}$ \\
\hline & 4 & 0 & 0 & 0 & 0 & 1 \\
\hline
\end{tabular}

Voor de toestanden 1, 2 en 3 geldt dat het systeem, als die toestanden eenmaal verlaten zijn, er niet meer terugkeert. Voor elk van de toestanden 0 en 4 geldt dat het systeem, als een dergelijke toestand eenmaal bereikt is, in die toestand blijft. De toestanden 1, 2 en 3 zijn dus doorgangstoestanden; de toestanden 0 en 4 zijn absorberende toestanden.

De kans na oneindig veel overgangen vanuit een doorgangstoestand nog in een doorgangstoestand te zijn is gelijk aan nul. De kans na oneindig veel overgangen in een bepaalde absorberende toestand te zijn is afhankelijk van de uitgangstoestand. Als het systeem in Voorbeeld 3 reeds in toestand 3 verkeert is de kans toestand 4 te bereiken groter dan wanneer het systeem in toestand 1 is. Om de invariante kansverdeling voor een dergelijke Markovketen te bepalen herschrijven wij de matrix van overgangswhn door de absorberende toestanden voorop te zetten en de doorgangstoestanden achteraan. Voor Voorbeeld 3 luidt de matrix dan:

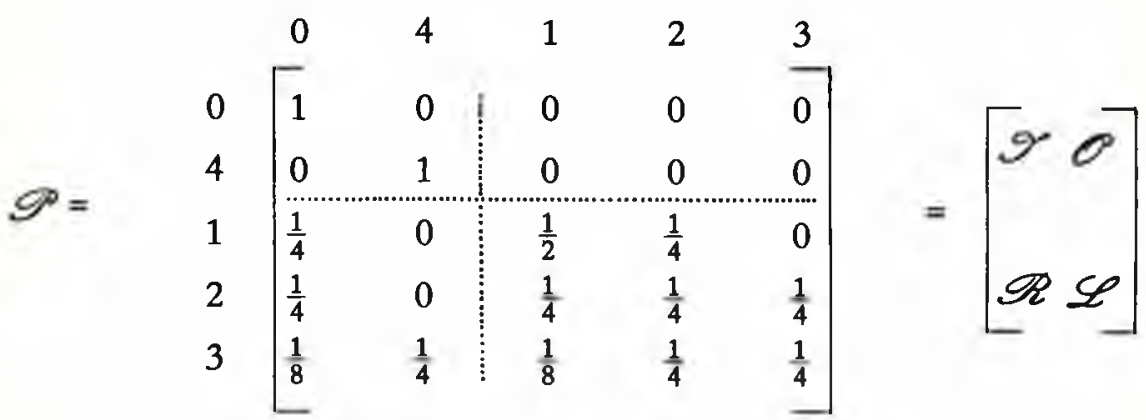

Hierin bevat de matrix $\mathscr{J}$ de overgangswhn als het proces in de absorberende toestanden is, $\mathscr{O}$ de overgangswhn van de absorberende toestanden naar 
de doorgangstoestanden, $\mathscr{R}$ de overgangswhn van de doorgangstoestanden naar de absorberende toestanden en $\mathscr{L}$ de overgangswhn als het proces in de doorgangstoestanden is. De limiet waartoe $\mathscr{P}^{\mathrm{m}}$ nadert heeft de volgende gedaante:

$\left.Q=\begin{array}{llllll}0 & 4 & 1 & 2 & 3 \\ 0 & 0 \\ 4 & 1 \\ 2 & 2 & 0 & 0 & 0 & 0 \\ 3 & 1 & 0 & 0 & 0 \\ \mathrm{q}_{10} & \mathrm{q}_{14} & 0 & 0 & 0 \\ \mathrm{q}_{20} & \mathrm{q}_{24} & 0 & 0 & 0 \\ \mathrm{q}_{30} & \mathrm{q}_{34} & 0 & 0 & 0\end{array}\right]$

Op dezelfde wijze waarop vergelijkingenstelsel (2.12) werd afgeleid kan worden aangetoond dat moet gelden dat:

$$
\mathrm{q}_{\mathrm{ij}}=\mathrm{p}_{\mathrm{ij}}+\sum_{\mathrm{k}} \mathrm{p}_{\mathrm{ik}} \mathrm{q}_{\mathrm{kj}}
$$

waarin $i$ een doorgangstoestand is, $j$ een absorberende toestand en $k$ de doorgangstoestanden doorloopt. Deze vergelijkingen maken het mogelijk de invariante kansen te berekenen. Wij lichten dit toe aan de hand van Voorbeeld 3 .

Voorbeeld 3 (vervolg)

Het vergelijkingenstelsel (2.13) wordt gegeven door:

$$
\begin{array}{ll}
\mathrm{q}_{10}=\frac{1}{4}+\frac{1}{2} \mathrm{q}_{10}+\frac{1}{4} \mathrm{q}_{20}, & \mathrm{q}_{14}=\frac{1}{2} \mathrm{q}_{14}+\frac{1}{4} \mathrm{q}_{24}, \\
\mathrm{q}_{20}=\frac{1}{4}+\frac{1}{4} \mathrm{q}_{10}+\frac{1}{4} \mathrm{q}_{20}+\frac{1}{4} \mathrm{q}_{30}, & \mathrm{q}_{24}=\frac{1}{4} \mathrm{q}_{14}+\frac{1}{4} \mathrm{q}_{24}+\frac{1}{4} \mathrm{q}_{34}, \\
\mathrm{q}_{30}=\frac{1}{8}+\frac{1}{8} \mathrm{q}_{10}+\frac{1}{4} \mathrm{q}_{20}+\frac{1}{4} \mathrm{q}_{30}, & \mathrm{q}_{34}=\frac{1}{4}+\frac{1}{8} \mathrm{q}_{14}+\frac{1}{4} \mathrm{q}_{24}+\frac{1}{4} \mathrm{q}_{34} .
\end{array}
$$

Omdat geldt dat:

$$
\mathrm{q}_{\mathrm{i} 0}+\mathrm{q}_{\mathrm{i} 4}=1, \quad \mathrm{i}=1,2,3,
$$

behoeft slechts één van beide drietallen vergelijkingen expliciet te worden opgelost. De oplossing van het tweede stelsel luidt:

$$
q_{14}=\frac{2}{25}, q_{24}=\frac{4}{25}, q_{34}=\frac{2}{5} \text {. }
$$


Het deel van het debiteurentegoed waarvan moet worden verwacht dat het oninbaar zal blijken is dus gelijk aan:

$$
\frac{2}{25} \cdot 0,50+\frac{4}{25} \cdot 0,30+\frac{2}{5} \cdot 0,20=0,168 .
$$

Als de Markovketen periodiek is bestaat $\operatorname{de} \lim _{m \rightarrow \infty} p_{i j}^{(m)}$ niet omdat $p_{i j}^{(m)}$ afwisselend nul en positief is afhankelijk van de waarde van $\mathrm{m}$. Wel bestaat dan:

(2.14) $\lim _{m \rightarrow \infty} \frac{-1}{m} \sum_{k=1}^{m} p_{i j}^{(k)}$.

Deze z.g. Cesarolimiet voor de overgangswhn kan op dezelfde wijze worden bepaald als de gewone limiet. Wij lichten dat toe aan de hand van Voorbeeld 4.

\section{Voorbeeld 4}

Een machine is steeds in één van drie mogelijke toestanden: (1) de machine is in bedrijf en draait; (2) de machine is in bedrijf en staat stil in afwachting van werk; (3) de machine is buiten bedrijf en wordt gerepareerd. Als de machine wordt gerepareerd, ligt na afloop van de reparatie steeds werk te wachten. De machine raakt tijdens stilstand in afwachting van werk niet buiten bedrijf. Als de machine draait, vindt er met gelijke whn een overgang plaats naar stilstand in afwach ting van werk of stilstand wegens defect.

Als wij de machine waarnemen op de tijdstippen dat de toestandsovergangen plaatsvinden, kan de rij van achtereenvolgens doorlopen toestanden worden beschreven met behulp van een enkelvoudige Markovketen met als matrix van overgangswhn:

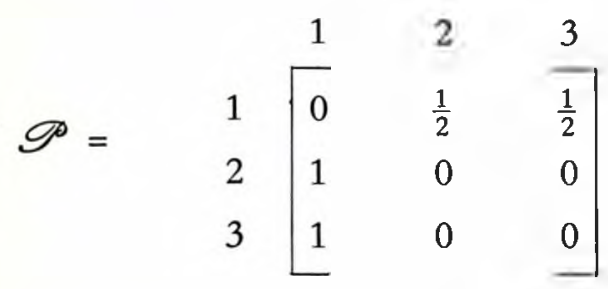

De matrix van overgangswhn in een even aantal overgangen wordt gegeven door:

$$
\mathscr{P}(2 \mathrm{~m})=\begin{aligned}
& 1 \\
& 1 \\
& 2 \\
& 3
\end{aligned}\left[\begin{array}{lll}
1 & 0 & \frac{3}{0} \\
0 & \frac{1}{2} & \frac{1}{2} \\
0 & \frac{1}{2} & \frac{1}{2}
\end{array}\right] \quad \mathrm{m}=1,2, \ldots
$$


en de matrix van overgangswhn in een oneven aantal overgangen door:

$$
\mathscr{P}^{(2 \mathrm{~m}+1)=} \begin{aligned}
& 1 \\
& 2 \\
& 3
\end{aligned}\left[\begin{array}{lll}
1 & 2 & 3 \\
0 & \frac{1}{2} & \frac{1}{2} \\
1 & 0 & 0 \\
1 & 0 & 0
\end{array}\right] \quad \mathrm{m}=1,2, \ldots
$$

Als een zeer groot aantal overgangen heeft plaatsgevonden en wij niet weten of dat aantal even of oneven is, worden de kansen op een verblijf in een bepaalde toestand gegeven door:

$\lim _{\mathrm{m} \rightarrow \infty} \frac{\mathscr{P}(2 \mathrm{~m})+\mathscr{P}(2 \mathrm{~m}+1)}{2}=\left[\begin{array}{lll}\frac{1}{2} & \frac{1}{4} & \frac{1}{4} \\ \frac{1}{2} & \frac{1}{4} & \frac{1}{4} \\ \frac{1}{2} & \frac{1}{4} & \frac{1}{4}\end{array}\right]$

Omdat elke toestand vanuit elke toestand kan worden bereikt, passen wij (2.12) toe op de matrix $\mathscr{P}$ van overgangswhn. Dit leidt tot:

$$
\begin{aligned}
& \mathrm{q}_{1}=\mathrm{q}_{2}+\mathrm{q}_{3}, \\
& \mathrm{q}_{2}=\frac{1}{2} \mathrm{q}_{1}, \\
& \mathrm{q}_{3}=\frac{1}{2} \mathrm{q}_{1}
\end{aligned}
$$

en:

$$
q_{1}+q_{2}+q_{3}=1
$$

zodat:

$$
q_{1}=\frac{1}{2}, q_{2}=\frac{1}{4}, q_{3}=\frac{1}{4}
$$

In geval van periodiciteit kunnen de invariante kansen dus op de gebruikelijke wijze met behulp van de matrix van overgangswhn worden bepaald.

\section{Toepassingen van de theorie van de Markovketens}

In paragraaf 2 hebben wij gezien hoe de invariante kansverdeling kan worden bepaald. In deze paragraaf zal worden uitgelegd waarvoor wij die verdeling nodig hebben. Daarbij wordt gebruik gemaakt van Voorbeeld 2.

Voorbeeld 2 (vervolg)

Stel de voorraadkosten gelijk aan één gulden per eenheid die aan het eind van 
een week in voorraad ligt, de vaste bestelkosten gelijk aan vijf gulden en de noodinkoopkosten gelijk aan 10 gulden meer dan de normale inkoopprijs per eenheid. In de toestanden 3,2 en 1 is er slechts sprake van voorraadkosten, zodat de kosten van een verblijf van een week in toestand 3, 2 resp. 1 gegeven worden door:

$$
x(3)=3, x(2)=2, x(1)=1 \text {. }
$$

In de toestanden $0,-1$ en -2 is er sprake van bestelkosten en in de toestanden -1 en -2 bovendien van noodinkoopkosten, zodat:

$$
x(0)=5, x(-1)=15, x(-2)=25 \text {. }
$$

De kosten van het systeem in de loop van een week zijn dus afhankelijk van de toestand waarin het systeem aan het eind van de week verkeert. Men kan bewijzen dat als het systeem gedurende een zeer groot aantal weken volgens het beschreven proces functioneert de gemiddelde kosten per week naderen tot:

$$
\text { (3.1) } \sum_{j=1}^{n} q_{i j} \times(j) \text {, }
$$

als de begintoestand $i$ is. Als de invariante kansen onafhankelijk zijn van de begintoestand naderen de gemiddelde kosten per week tot:

$$
\sum_{j=1}^{n} q_{j} \times(j) \text {. }
$$

De gemiddelde kosten per week van het beschouwde systeem zijn dus gelijk aan:

$$
\frac{9}{64} \cdot 3+\frac{3}{16} \cdot 2+\frac{1}{4} \cdot 1+\frac{1}{4} \cdot 5+\frac{7}{64} \cdot 15+\frac{1}{16} \cdot 25=5 \frac{1}{2} .
$$

Wij kunnen nu nagaan wat de consequenties in termen van kosten zijn als men niet pas aanvult als de voorraad gelijk is aan nul exemplaren, maar reeds als de voorraad gelijk is aan één exemplaar. De matrix van overgangswhn wordt dan gegeven door:

$\left.\mathscr{P}=\begin{array}{ccccccc}3 & 3 & 2 & 1 & 0 & -1 \\ 2 & 1 \\ 1 & 0 \\ -1 & 0 & \frac{1}{4} & \frac{1}{4} & \frac{1}{4} & 0 \\ \frac{1}{4} & \frac{1}{4} & \frac{1}{4} & \frac{1}{4} & \frac{1}{4} \\ 0 & \frac{1}{4} & \frac{1}{4} & \frac{1}{4} & 0 \\ \frac{1}{4} & \frac{1}{4} & \frac{1}{4} & \frac{1}{4} & 0 \\ \frac{1}{4} & \frac{1}{4} & \frac{1}{4} & \frac{1}{4} & 0\end{array}\right]$


waaruit kan worden afgeleid dat de invariante kansen gelijk zijn aan:

$$
q_{3}=\frac{3}{16}, q_{2}=\frac{1}{4}, q_{1}=\frac{1}{4}, q_{0}=\frac{1}{4}, q_{-1}=\frac{1}{16} \text {. }
$$

De kosten van een verblijf gedurende een week in elk van de toestanden zijn:

$$
x(3)=3, x(2)=2, x(1)=6, x(0)=5, x(-1)=15,
$$

zodat de gemiddelde kosten per week naderen tot:

$$
\frac{3}{16} \cdot 3+\frac{1}{4} \cdot 2+\frac{1}{4} \cdot 6+\frac{1}{4} \cdot 5+\frac{1}{16} \cdot 15=4 \frac{3}{4} .
$$

Het blijkt dus voordelig reeds te gaan aanvullen als er nog één exemplaar in voorraad ligt. Op dezelfde wijze kan men nagaan dat als men reeds aanvult bij een voorraad van twee exemplaren de gemiddelde kosten per week naderen tot $5 \frac{1}{4}$, zodat het bij een aanvulling tot drie exemplaren aanbeveling verdient aan te vullen als de voorraad aan het eind van de week één exemplaar bedraagt of minder.

Indien het proces van een systeem dat beschreven kan worden met behulp van een stationaire enkelvoudige Markovketen gekenmerkt wordt door een zeer groot aantal overgangen is het mogelijk de gemiddelde opbrengst per overgang te bepalen aan de hand van de invariante kansverdeling. Indien het mogelijk is op verscheidene wijzen in het proces in te grijpen kan de gemiddelde opbrengst per overgang worden gebruikt als criterium om de optimale wijze van ingrijpen te bepalen.

Indien er sprake is van een groot aantal mogelijke wijzen van ingrijpen impliceert het bepalen van de invariante kansen een grote hoeveelheid rekenwerk. Dat rekenwerk kan worden vermeden door gebruik te maken van een door R. A. HOWARD ontwikkeld algoritme dat uitgaande van een bepaalde manier van ingrijpen op eenvoudige wijze een betere manier bepaalt en aldus in eindig veel stappen de optimale wijze van ingrijpen opspoort.

In Voorbeeld 3 werden de invariante kansen niet bepaald omdat in het proces moest worden ingegrepen maar omdat een indicatie moest worden verkregen van de orde van grootte van de benodigde voorziening voor dubieuze debiteuren. In een dergelijk geval wordt het Markovketenmodel niet gebruikt om te optimaliseren maar om te analyseren. Een ander voorbeeld daarvan kan worden aangetroffen bij de analyse van wachttijdsituaties. Wachttijdsituaties kunnen ontstaan waar een faciliteit voor gemeenschappelijk gebruik wordt geïnstalleerd. Mensen of dingen komen bij de faciliteit aan en oefenen een vraag uit naar bepaalde diensten. De aankomenden (de klanten) moeten wachten als de faciliteit in gebruik is. De faciliteit is het systeem waarvan de toestand wordt weergegeven door het aantal klanten dat een klant die na gebruik van de faciliteit vertrekt achter zich laat. Onder enige algemene voorwaarden is het mogelijk het systeem te beschrijven met behulp van een enkelvoudige Markovketen, de matrix van overgangswhn op te stellen, de invariante kansverdeling te bepalen en met behulp daarvan een 
aantal karakteristieke grootheden af te leiden aan de hand waarvan kan worden beoordeeld of het systeem naar behoren functioneert.

Met betrekking tot zowel optimalisering als analysering is intussen een indrukwekkende reeks toepassingsmogelijkheden bekend. Artikelen in verscheidene tijdschriften doen daarvan regelmatig verslag. Wie zich nader wil oriënteren omtrent de beginselen van de theorie van de Markovketens kan terecht in elke inleiding in de toepassing van wiskundige methoden bij de beslissingsvoorbereiding en voorts onder meer in:

G. De Leve, W. Molenaar, Markovketens en Wachttijden, 2e druk, Amsterdam, 1969.

J. Kemeny, J. Snell, Finite Markov Chains. Princeton, 1960.

R. Howard, Dynamic Programming and Markov Processes. New York, 1960. 